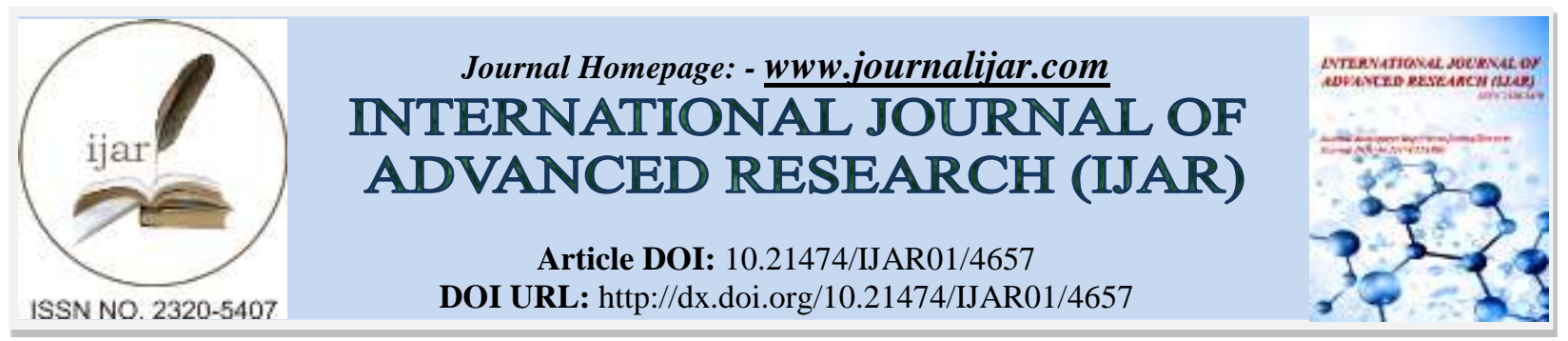

RESEARCH ARTICLE

\title{
HEAVY METAL CONTENT VARIATIONS IN TOTAL SUSPENDED PARTICLES AND SEDIMENT DUST IN ZENICA CITY DURING 11 YEARS PERIOD 2006 - 2016.
}

Mirnes Durakovic, Sanela Beganovic and Halim Prcanovic, University of Zenica, Metallurgical Institute "Kemal Kapetanović", Zenica, Bosnia and Herzegovina.

\section{Manuscript Info}

Manuscript History

Received: 26 April 2017

Final Accepted: 29 May 2017

Published: June 2017

Key words:-

total suspended particles, sedimented dust, heavy metal, air pollution, Steel Works Zenica

\section{Abstract}

This study presents results of eleven years measurement of sediment dust and total suspended particles campaign, conducted in two places in Zenica City between January 12006 and December 312016. Samples of total suspended particles and sediment dust were analyzed for three heavy metals (iron, lead and cadmium). Concentrations of cadmium and lead have been measured because they are very much present in polluted areas with steel works. Since iron is not considered as a pollutant, it was measured to track impact of Steel Works on environment. Total suspended particles were measured using German standard VDI 2463 Blatt 4. Sediment dust was measured using Bergerhoff method. Collected samples were analyzed for iron, lead, and cadmium in the chemical laboratory of the Metallurgical Institute "Kemal Kapetanović" Zenica using standard methods. The heavy metal TSP/SD ratio shows that lead and cadmium are present in a higher proportion in TSP than in SD, whereas Iron is present in higher proportion in SD. Analysis of temporal variations of TSP, SD and heavy metals showed uprising trend of pollution in Zenica city.

Copy Right, IJAR, 2017,. All rights reserved.

\section{Introduction:-}

Zenica City is one of the most polluted cities in Bosnia and Herzegovina due to mining and metallurgic activities, great number of boilers, small house stoves and traffic. Steel Works Arcelor Mittal Zenica is located in urban zone next to the residential buildings. These activities, especially metallurgic, emit a high amount of dust with considerable concentrations of heavy metals. When we consider metal in total suspended particles (TSPs) and in sediment dust (SD), the situation is worse in the areas around Steel Works Zenica. This is because particulate matter (PM) contain many heavy fractions which literally "cross the fence" of Steel Works. That is the reason why the effects of repair of the main sources of dust emissions at the Steel Works Zenica in 1987 brought a significant reduction of sediment dust, especially at measurement locations around the Steel Works [1]. The situation deteriorates in the winter due to the heating season and meteorological conditions (temperature inversions), which are typical for for the deep valley terrain. Zenica is situated in 600 meters of deep valley bordered with high hills. Atmospheric conditions in autumn and winter favor the accumulation of pollutants in the valleys, in a phenomenon known as air mass stagnation $[2,3]$.

Over the past 20 years a number of studies [4-7] have proven that particulate matter poses a significant treat on human health. Elevated concentrations of lead can induce severe neurological and hematological effects to the 
exposed population and especially children. The main emission source of lead in the atmosphere for many years has been the use of ore with high content of lead in Steel Works Zenica, and use of leaded gasoline in vehicles. Since the lead content in fuels has been regulated during the past years, industrial sources and fuel burning activities have assumed a bigger importance in ambient lead production. Compounds of cadmium are susceptible for inducing carcinogenic effects in humans, through inhalation. Chronic exposure toxicity effects of cadmium compounds are local irritation of the lungs and gastrointestinal tract, kidney damage and abnormalities of skeletal system [5]. Cadmium compounds in particulate matter, mainly originate from coal and fuel oil combustion processes, metallurgical industry, and road transport [8].

There are short-term measurements conducted in Zenica City in a considered period with more element analysis [9], but due to the limited resources assigned for continual air quality monitoring; only $\mathrm{Pb}, \mathrm{Cd}$ and $\mathrm{Fe}$ are analyzed simultaneously in SD and TSP-s during entire considered period. These measurements reveal that concentrations of other heavy metals like nickel, chromium and manganese violate prescribed limits.

The aim of this paper is systematic analysis of the spatial and temporal variability of toxic metal concentrations in SD and TSP, in Zenica City. Initial comparison with the recent ambient assessment thresholds set up by the domestic regulations for $\mathrm{Pb}$ and $\mathrm{Cd}$, was also performed. All data used in this study are the outcome of measurements of Metallurgical institute "Kemal Kapetanović" Zenica[10].

\section{Methodology:-}

The measurement campaign was conducted from January 12006 to December 312016 in two places "TETOVO" and "INSTITUT" (Figure 1). Measurement site "TETOVO" is located near the Steel Works (Figure $1 \mathrm{a}$ ), $350 \mathrm{~m}$ from basic oxygen furnace (BOF). The second location "INSTITUT" is a measurement site located in urban part of the city. This measurement site was chosen because it is located north of the steel works and detects pollution that the north wind, which blows approximately $11.2 \%$ of the time, carries from the Steel Works to the city. Therefore, when it comes to pollution from Steel Works, this measuring site is always considered as a representative for the city [10]. Sediment dust was measured on seven other locations distributed along the Zenica valley, as shown in Figure 1 .

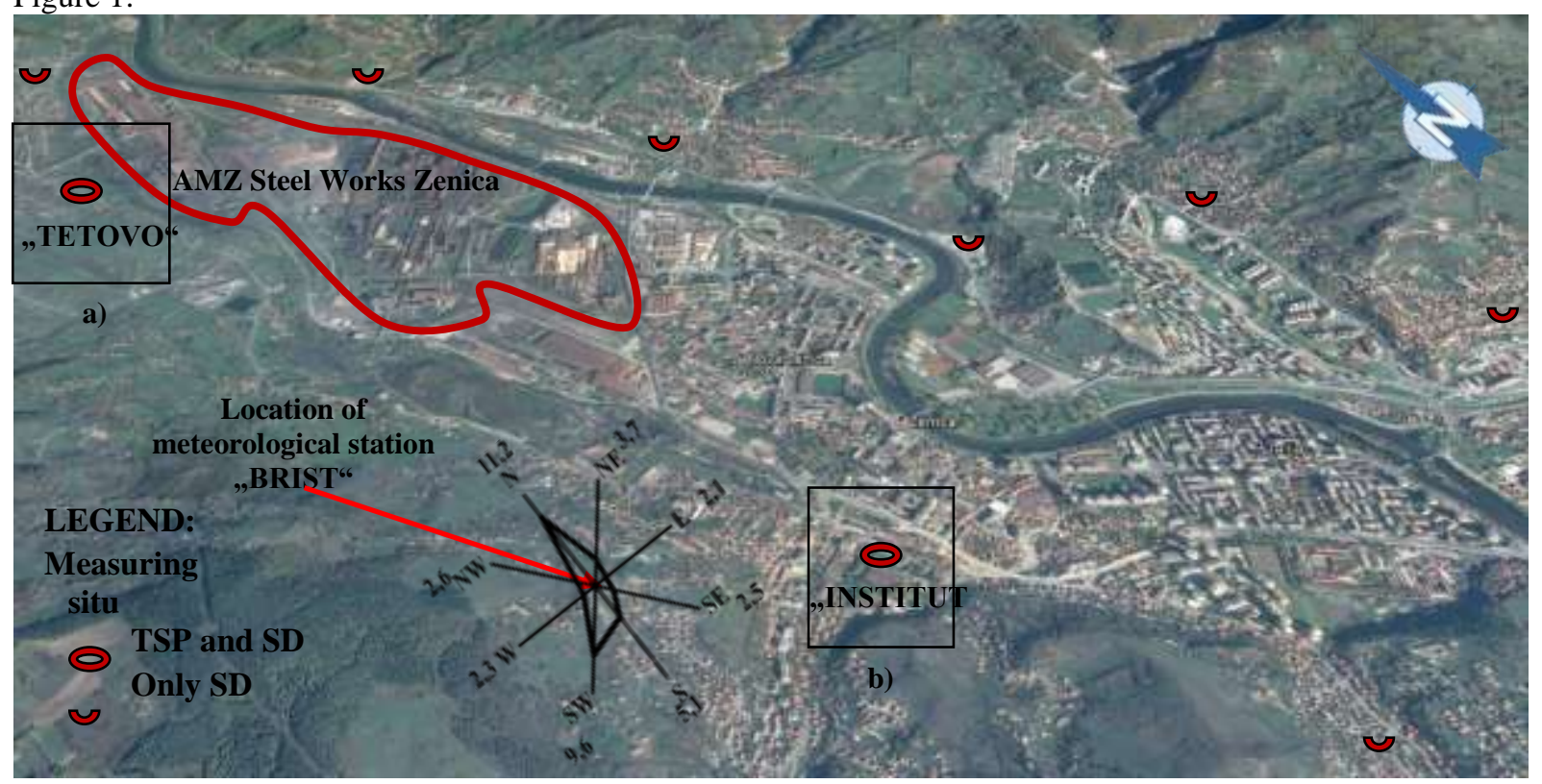




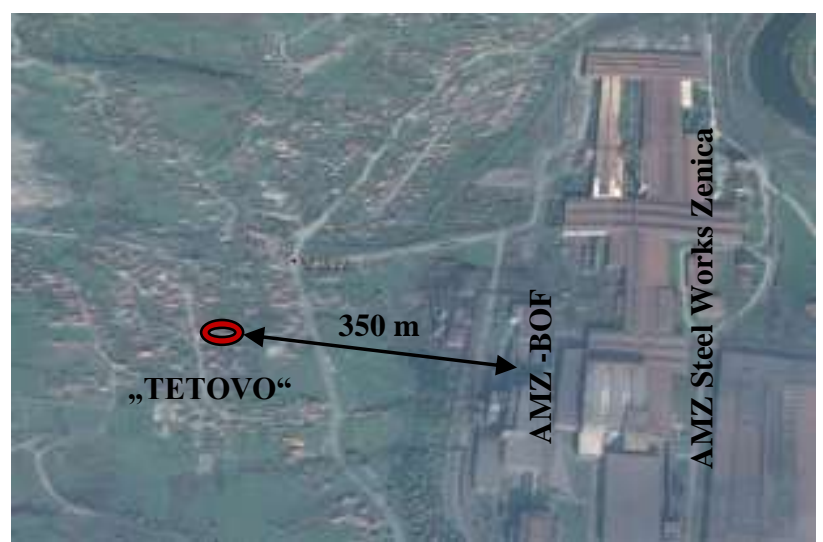

a)

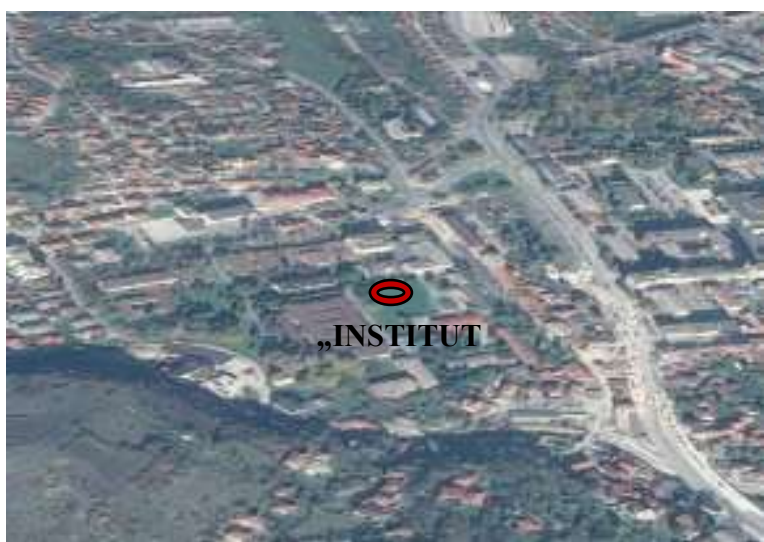

b)

Figure 1:- Study area and spatial distribution of measurement sties

\section{Results and Discussion:-}

Results of TSP and SD measurements are shown in Table 1. and 2. The highest average of TSP in the eleven year period was found in "TETOVO" with total concentration of $154 \mu \mathrm{g} / \mathrm{m}^{3}$. The highest concentration of SD was also found in "TETOVO" with concentration of $785 \mathrm{mg} / \mathrm{m} 2 \mathrm{dan}$. Data clearly indicates that concentrations of cadmium were significantly higher in period 2006-2008 in both measurement places, whereas lead was significantly higher in measurement site "TETOVO". It should be noted that integral production in steel works Zenica was started in late 2008, and in period 2006-2008 steel works Zenica was working with 100 ton electric blast furnace, which was stopped after the start of integral production. On the other hand, concentration of iron increased after the start of integral production especially in SD and in measurement site "TETOVO" which is located near the steel works

Table 1:- Year average of TSP, SD and heavy metal concentrations in measurements site "INSTITUT"

\begin{tabular}{|c|c|c|c|c|c|c|c|c|}
\hline YEAR & $\mathbf{T S P}$ & $\mathbf{S D}$ & $\mathbf{F e}_{\text {TSP }}$ & $\mathbf{F e}_{\text {SD }}$ & $\mathbf{C d}_{\text {TSP }}$ & $\mathbf{C d}_{\text {SD }}$ & $\mathbf{P b}_{\text {TSP }}$ & $\mathbf{P b}_{\text {SD }}$ \\
\hline- & $\mathbf{\mu g} / \mathbf{m}^{\mathbf{3}}$ & $\mathbf{m g} \mathbf{m}^{\mathbf{2}} \mathbf{d a y}$ & $\mathbf{\%}$ & $\mathbf{\%}$ & $\mathbf{\%}$ & $\mathbf{\%}$ & $\mathbf{\%}$ & $\mathbf{\%}$ \\
\hline 2006 & 70 & 165 & 1,917 & 3,2600 & 0,0595 & 0,0010 & 0,219 & 0,054 \\
\hline 2007 & 70 & 101 & 2,154 & 3,0650 & 0,032 & 0,0030 & 0,307 & 0,047 \\
\hline 2008 & 85 & 165 & 4,275 & 12,570 & 0,150 & 0,0010 & 0,139 & 0,033 \\
\hline 2009 & 86 & 166 & 5,737 & 11,330 & 0,011 & 0,0010 & 0,158 & 0,018 \\
\hline 2010 & 90 & 284 & 7,760 & 7,0880 & 0,001 & 0,0003 & 0,145 & 0,028 \\
\hline 2011 & 105 & 193 & 5,285 & 6,4690 & 0,004 & 0,0004 & 0,096 & 0,026 \\
\hline 2012 & 103 & 204 & 4,230 & 10,145 & 0,005 & 0,0001 & 0,121 & 0,023 \\
\hline 2013 & 104 & 218 & 5,160 & 10,583 & 0,012 & 0,0010 & 0,233 & 0,025 \\
\hline 2014 & 99 & 338 & 5,564 & 7,7370 & 0,009 & 0,0010 & 0,094 & 0,020 \\
\hline 2015 & 105 & 346 & 6,625 & 15,190 & 0,013 & 0,0010 & 0,063 & 0,019 \\
\hline 2016 & 107 & 412 & 4,790 & 14,200 & 0,010 & 0,0010 & 0,045 & 0,014 \\
\hline
\end{tabular}

Table 2;- Year average of TSP, SD and heavy metal concentrations in measurements site "TETOVO"

\begin{tabular}{|c|c|c|c|c|c|c|c|c|}
\hline YEAR & $\mathbf{T S P}$ & $\mathbf{S D}$ & $\mathbf{F e}_{\text {TSP }}$ & $\mathbf{F} \mathbf{e}_{\text {SD }}$ & $\mathbf{C d _ { \text { TSP } }}$ & $\mathbf{\mathbf { C d } _ { \text { SD } }}$ & $\mathbf{P b}_{\mathbf{T S P}}$ & $\mathbf{P b}_{\text {SD }}$ \\
\hline- & $\mathbf{\mu g} / \mathbf{m}^{\mathbf{3}}$ & $\mathbf{m g} / \mathbf{m}^{\mathbf{2}} \mathbf{d a y}$ & $\mathbf{\%}$ & $\mathbf{\%}$ & $\mathbf{\%}$ & $\mathbf{\%}$ & $\mathbf{\%}$ & $\mathbf{\%}$ \\
\hline 2006 & 84 & 231 & 3,4220 & 3,5630 & 0,026 & 0,0010 & 0,510 & 0,050 \\
\hline 2007 & 83 & 168 & 4,5660 & 3,2050 & 0,056 & 0,0070 & 0,985 & 0,077 \\
\hline 2008 & 88 & 204 & 8,3550 & 11,465 & 0,018 & 0,0020 & 0,288 & 0,046 \\
\hline 2009 & 96 & 294 & 12,202 & 13,618 & 0,013 & 0,0010 & 0,215 & 0,041 \\
\hline 2010 & 107 & 302 & 9,0800 & 10,590 & 0,003 & 0,0003 & 0,097 & 0,023 \\
\hline 2011 & 140 & 307 & 9,2570 & 10,618 & 0,004 & 0,0010 & 0,112 & 0,043 \\
\hline 2012 & 146 & 370 & 12,431 & 12,798 & 0,004 & 0,0010 & 0,195 & 0,033 \\
\hline 2013 & 131 & 300 & 10,806 & 11,203 & 0,010 & 0,0010 & 0,213 & 0,045 \\
\hline 2014 & 106 & 503 & 10,769 & 9,683 & 0,010 & 0,0010 & 0,125 & 0,024 \\
\hline 2015 & 131 & 785 & 10,439 & 20,550 & 0,011 & 0,0010 & 0,077 & 0,025 \\
\hline 2016 & 154 & 664 & 8,6890 & 14,523 & 0,007 & 0,0011 & 0,059 & 0,026 \\
\hline
\end{tabular}


Table 3 shows the TSP/SD ratio for each station and the average ratio for each metal in TSP and SD. It should be noted that lead and cadmium are in a higher proportion in the TSP, especially in measurement site "INSTITUT" which is located in an urban part of the city. Iron is in higher proportion in SD especially in measurement site "TETOVO". The percentage for $\mathrm{Cd}$, and $\mathrm{Pb}$ in TSP is considerably higher than in SD. Cadmium is an average of 30,77 times higher in TSP in measurement site "INSTITUT" and 10,1 times in measurement situ "TETOVO". Lead is an average of 5,3 times higher in TSP in measurement site "INSTITUT" and 5,68 times in measurement site “TETOVO". According to Mugica et all [11] Cd and $\mathrm{Pb}$ are present preferably in the respirable part of suspended particles and could be a health risk. Therefore, investigation of PM10 to TSP ratio in Zenica city is important, because the content of heavy metals is within the limits prescribed by the domestic regulations. Since the thresholds for metal content in PM10 are stricter, it is necessary to determine heavy metal content in PM10 particles, to see whether the limits are violated.

Table 3:- TSP/SD ratio and heavy metal in TSP/heavy metal in SD ratio.

\begin{tabular}{|c|c|c|c|c|c|c|c|c|}
\hline \multirow[t]{3}{*}{ YEAR } & \multicolumn{4}{|c|}{ Measurement site "INSTITUT" } & \multicolumn{4}{|c|}{ Measurement site "TETOVO" } \\
\hline & TSP & $\mathrm{Fe}_{\mathrm{TSP}}$ & $\mathrm{Cd}_{\mathrm{TSP}}$ & $\mathrm{Pb}_{\mathrm{TSP}}$ & TSP & $\mathrm{Fe}_{\mathrm{TSP}}$ & $\mathrm{Cd}_{\mathrm{TSP}}$ & $\mathrm{Pb}_{\mathrm{TSP}}$ \\
\hline & SD & $\mathrm{Fe}_{\mathrm{SD}}$ & $\mathrm{Cd}_{\mathrm{SD}}$ & $\mathrm{Pb}_{\mathrm{SD}}$ & $\mathrm{SD}$ & $\mathrm{Fe}_{\mathrm{SD}}$ & $\mathrm{Cd}_{\mathrm{SD}}$ & $\mathrm{Pb}_{\mathrm{SD}}$ \\
\hline 2006 & 0,42 & 0,59 & 59,50 & 4,06 & 0,36 & 0,96 & 26,0 & 10,20 \\
\hline 2007 & 0,69 & 0,70 & 10,67 & 6,53 & 0,49 & 1,42 & 8,00 & 12,79 \\
\hline 2008 & 0,52 & 0,34 & 150,0 & 4,21 & 0,43 & 0,73 & 9,00 & 6,26 \\
\hline 2009 & 0,52 & 0,51 & 11,00 & 8,78 & 0,33 & 0,90 & 13,0 & 5,24 \\
\hline 2010 & 0,32 & 1,09 & 3,330 & 5,18 & 0,35 & 0,86 & 10,0 & 4,22 \\
\hline 2011 & 0,54 & 0,82 & 10,00 & 3,69 & 0,46 & 0,87 & 4,00 & 2,60 \\
\hline 2012 & 0,50 & 0,42 & 50,00 & 5,26 & 0,39 & 0,97 & 4,00 & 5,91 \\
\hline 2013 & 0,48 & 0,49 & 12,00 & 9,32 & 0,44 & 0,96 & 10,0 & 4,73 \\
\hline 2014 & 0,29 & 0,72 & 9,00 & 4,70 & 0,21 & 1,11 & 10,0 & 5,21 \\
\hline 2015 & 0,30 & 0,44 & 13,00 & 3,32 & 0,17 & 0,51 & 11,0 & 3,08 \\
\hline 2016 & 0,26 & 0,34 & 10,00 & 3,21 & 0,23 & 0,60 & 6,36 & 2,27 \\
\hline $\mathrm{AVG}$ & 0,44 & 0,59 & 30,77 & 5,30 & 0,35 & 0,90 & 10,1 & 5,68 \\
\hline
\end{tabular}

The relationship between chemical elements in TSP and SD was assessed with the Pearson's coefficient of correlation $r$ between their contents in the samples (Table 4.). It was qualitatively assumed that the absolute values of $r$ between 0,3 and 0,7 indicate good association, and those between 0,7 and 1,0 strong association between elements [12]. If the coefficient between two metals is high, this means that the origin of emission for both metals is the same. Table 4 shows that highest correlation is between lead and cadmium in measurement site "TETOVO" $\left(\mathrm{Pb}_{\mathrm{TSP}}-\mathrm{Pb}_{\mathrm{SD}}=0,92 ; \mathrm{Pb}_{\mathrm{TSP}}-\mathrm{Cd}_{\mathrm{SD}}=0,89 ; \mathrm{Pb}_{\mathrm{SD}}-\mathrm{Cd}_{\mathrm{SD}}=0,83 ; \mathrm{Pb}_{\mathrm{SD}}-\mathrm{Cd}_{\mathrm{TSP}}=0,87 ; \mathrm{Pb}_{\mathrm{TSP}}-\mathrm{Cd}_{\mathrm{TSP}}=0,97 ; \mathrm{Cd}_{\mathrm{SD}}-\mathrm{Cd}_{\mathrm{TSP}}=0,92\right)$. On the other hand, correlation coefficients in measurement site "INSTITUT" are significantly smaller. It is interesting that the correlation coefficients between iron and other elements in SD or TSP in this measurement site is smaller and has negative values, which means that high concentrations of iron correspond to low concentrations of other two elements. The reason for this could be the location of measurement site "INSTITUT", which is located in the urban part of the city. Clearly, there are different emission sources in this Measurement site. Research [10] show that concentration of iron in TSP has raised, after the start of integral production in steel works Zenica. Therefore, it is clear that concentration of iron in TSP and SD is directly connected to steel works activities 
Table 3:- TSP/SD ratio and heavy metal in TSP/heavy metal in SD ratio

\begin{tabular}{|c|c|c|c|c|c|c|c|c|}
\hline- & TSP & SD & $\mathrm{Fe}_{\mathrm{TSP}}$ & $\mathrm{Fe}_{\mathrm{SD}}$ & $\mathrm{Cd}_{\mathrm{TSP}}$ & $\mathrm{Cd}_{\mathrm{SD}}$ & $\mathrm{Pb}_{\mathrm{TSP}}$ & $\mathrm{Pb}_{\mathrm{SD}}$ \\
\hline \multicolumn{9}{|c|}{ Measurment site „INSTITUT“ } \\
\hline TSP & 1 & & & & & & & \\
\hline SD & 0,68 & 1 & & & & & & \\
\hline $\mathrm{Fe}_{\mathrm{TSP}}$ & 0,61 & 0,57 & 1 & & & & & \\
\hline $\mathrm{Fe}_{\mathrm{SD}}$ & 0,65 & 0,56 & 0,51 & 1 & & & & \\
\hline $\mathrm{Cd}_{\mathrm{TSP}}$ & $-0,47$ & $-0,39$ & $-0,41$ & 0,05 & 1 & & & \\
\hline $\mathrm{Cd}_{\mathrm{SD}}$ & $-0,58$ & $-0,34$ & $-0,55$ & $-0,33$ & 0,19 & 1 & & \\
\hline $\mathrm{Pb}_{\mathrm{TSP}}$ & $-0,74$ & $-0,77$ & $-0,58$ & $-0,66$ & 0,18 & 0,63 & 1 & \\
\hline $\mathrm{Pb}_{\mathrm{SD}}$ & $-0,85$ & $-0,67$ & $-0,74$ & $-0,77$ & 0,45 & 0,47 & 0,75 & 1 \\
\hline \multicolumn{9}{|c|}{ Measurement site „TETOVO“ } \\
\hline TSP & 1 & & & & & & & \\
\hline SD & 0,61 & 1 & & & & & & \\
\hline $\mathrm{Fe}_{\mathrm{TSP}}$ & 0,54 & 0,38 & 1 & & & & & \\
\hline $\mathrm{Fe}_{\mathrm{SD}}$ & 0,61 & 0,76 & 0,73 & 1 & & & & \\
\hline $\mathrm{Cd}_{\mathrm{TSP}}$ & $-0,66$ & $-0,43$ & $-0,72$ & $-0,65$ & 1 & & & \\
\hline $\mathrm{Cd}_{\mathrm{SD}}$ & $-0,44$ & $-0,37$ & $-0,53$ & $-0,52$ & 0,92 & 1 & & \\
\hline $\mathrm{Pb}_{\mathrm{TSP}}$ & $-0,64$ & $-0,59$ & $-0,72$ & $-0,76$ & 0,97 & 0,89 & 1 & \\
\hline $\mathrm{Pb}_{\mathrm{SD}}$ & $-0,54$ & $-0,70$ & $-0,62$ & $-0,69$ & 0,87 & 0,83 & 0,92 & 1 \\
\hline
\end{tabular}

Figure 2 shows temporal variations of annual averages of TSP and SD for both measuring sites. The uprising trend, in last six years concerning TSP and last three years concerning SD, especially in measurement site "TETOVO" is evident. Thresholds established by domestic regulations are: TSP $90 \mu \mathrm{g} / \mathrm{m}^{3}$ (year average), SD $200 \mathrm{mg} / \mathrm{m}^{2} \mathrm{day}$ (year average), are violated in period 2009 to 2016 in measurement site "TETOVO". Figure 2 shows that the amount of TSP is $23,36 \%$ more, and the amount of SD is $37,21 \%$ more in measurement site "TETOVO" than in measurement site "INSTITUT"
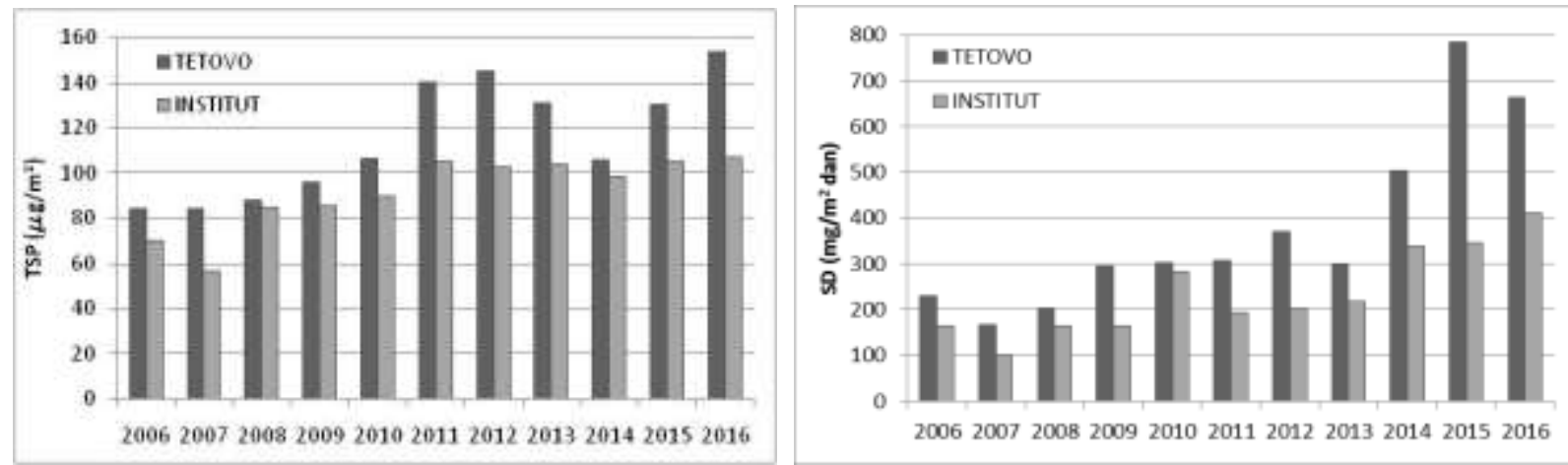

a) b)

Figure 2:- Temporal variations of: a) TSP and b) SD

Figure 3 shows temporal variations of annual averages of lead and cadmium for both measurement sites. After 2008, concentrations of cadmium and lead dropped significantly. In the past four years, Cadmium concentrations have raised in both measurement sites, whereas lead concentrations have downfall trend in both measurement sites 


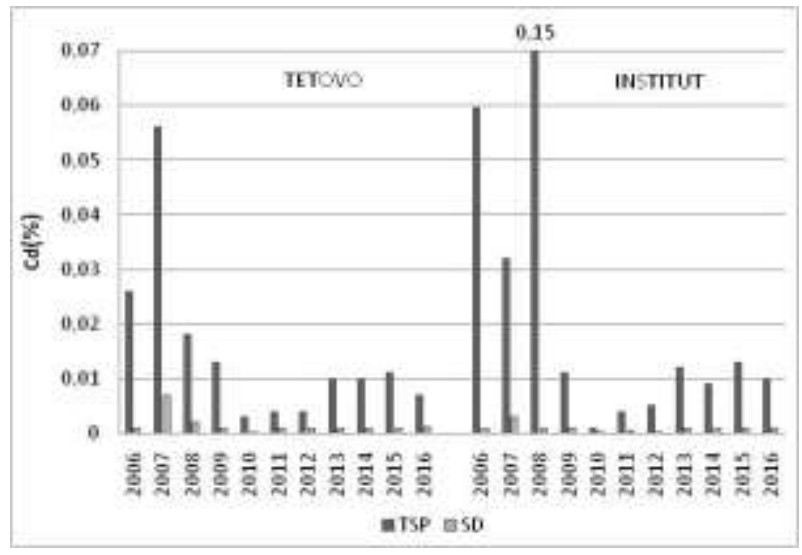

a)

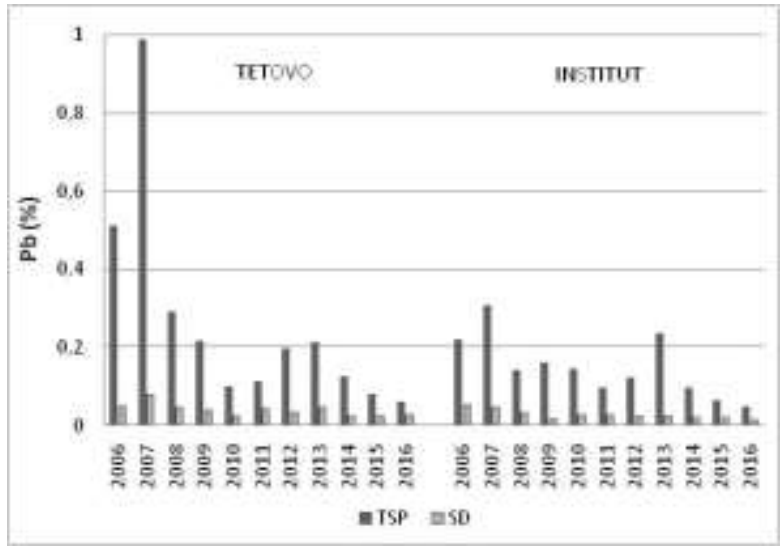

b)

Figure 3:- Temporal variations of: a) cadmium and b) lead in TSP and SD

Figure 4 shows variations of annual averages of iron for both measurement sites. As it can be seen amount of iron has risen after 2008 (start of integral production in Steel Works Zenica) in both measurement places. This increase is higher in measurement site "TETOVO", which is normal because of its location. In measurement situ "INSTITUT" the amount of iron in SD is up to 2,9 times as much as iron in TSP. Increase of iron in SD in the past two years is evident.

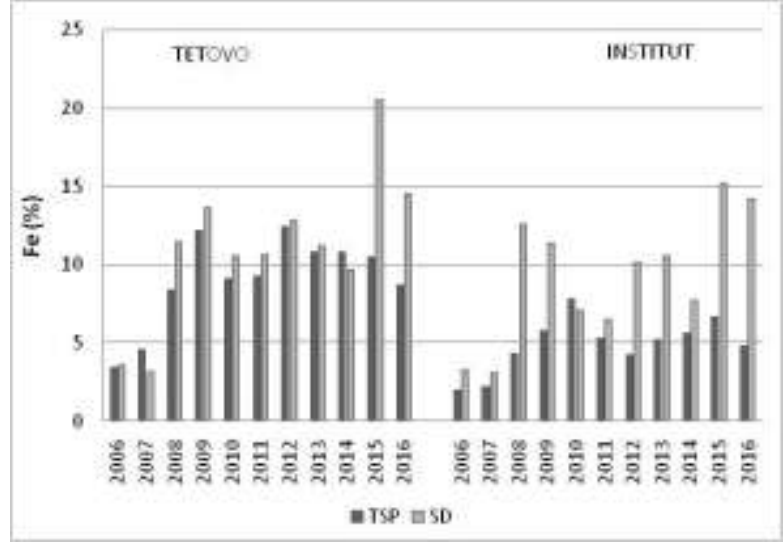

Figure 4:- Temporal variations of iron in TSP and SD

Figure 5 shows quarterly variations of TSP and SD. The first and fourth quarter belongs to cold part of the year and second and third quarter belongs to warm part of the year. First and fourth quarters of the year are part of heating season. This analysis is performed in order to investigate season specific variations of TSP, SD and metal content.
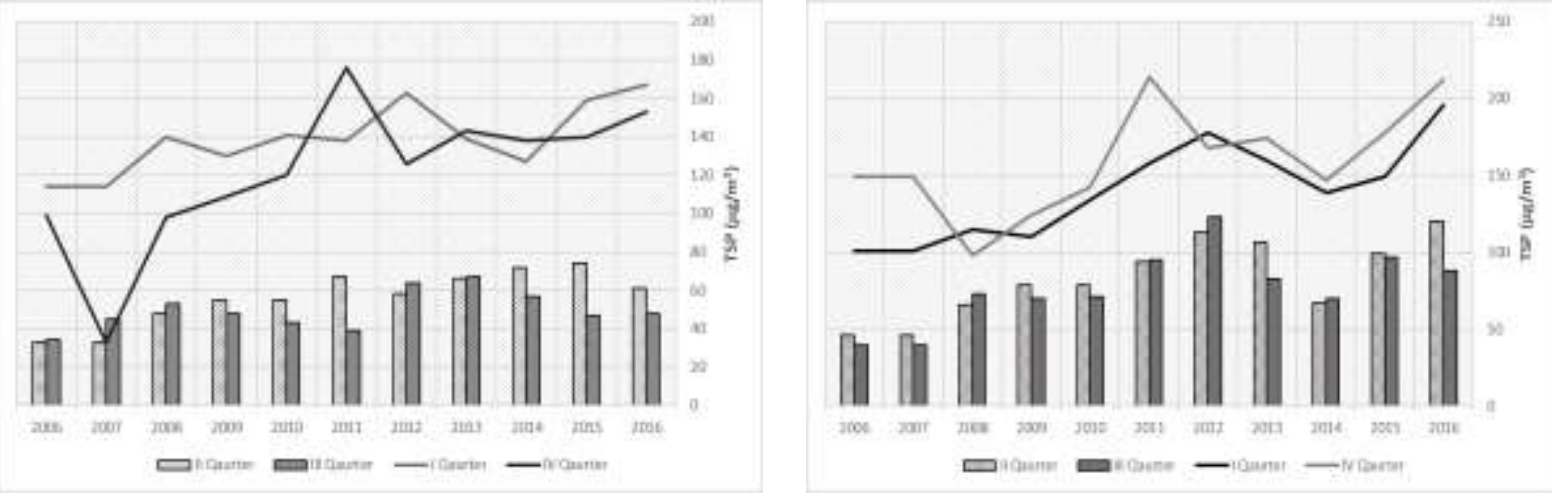


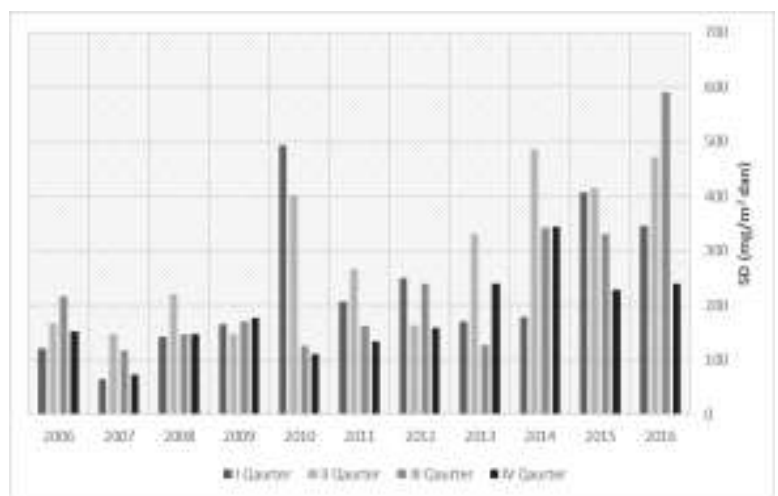

INSTITUT

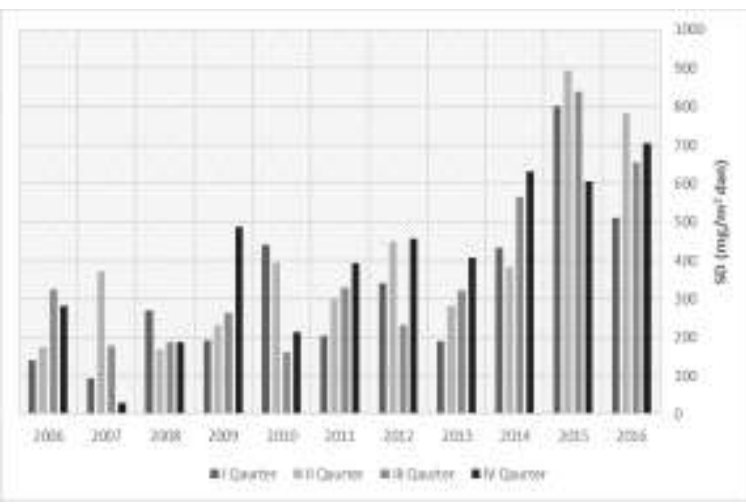

TETOVO

Figure 5:- Quarterly variations of TSP and SD

As it can be seen in Figure 5, the amount of TSP is 1,4 to 2,9 times higher than in the cold part of the year in the measurement site "INSTITUT". In measurement site "TETOVO" this proportion is even higher $(1,8$ to 3,1$)$. Seasonspecific patterns for SD are not very clear. Sometimes it is higher in the warm part of the year and sometimes is higher in cold part of the year. This random behavior of amount of SD could be connected with frequent still conditions in Zenica valley. Seasonal variations of heavy metal concentrations are also unclear.

\section{Conclusion:-}

This study was conducted to know temporal and spatial variation of lead, cadmium and iron on TSP and sedimented dust during an eleven years period in the city of Zenica. Suburb TETOVO is the most polluted part of Zenica city since it is located next to the fence of the steel works. The heavy metal TSP/SD ratio shows that lead and cadmium are present in a higher proportion in TSP than in SD, whereas Iron is present in a higher proportion in SD. The correlation analysis between metal concentrations, amount of TSP and SD showed a good correlation between Cd and $\mathrm{Pb}$ in measurement situ "TETOVO", while correlation between same elements in measurement situ "INSTITUT" were rather low, not allowing a clear explanation on the commonality of the sources. It is clear that in measurement situ "INSTITUT" metals emanate from multiple common origins. After the start of integral production in Steel Works Zenica concentrations of $\mathrm{Pb}$, and Cd dropped significantly. On the other hand, significant incline of iron concentrations especially in SD in Measurement situ "TETOVO" was recorded. Temporal analysis of TSP, SD and metal concentrations showed incline trend of pollution in Zenica city especially in the last two years. Quarterly variations analysis of TSP and CD, performed to analyze the periods of activation/deactivation of domestic heating as a source of pollution, showed increase of TSP during the cold part of the year. On the other hand quarterly variation analysis of SD and heavy metal concentrations was found to be inconclusive, and does not produce clear evidence on the association on heating season with heavy metals and SD. Domestic legislated limit values for metals in TSP were not violated. On the other hand limit values for annual average of TSP, SD and heavy metals in SD were violated. PM10 measurement and analysis on heavy metal in Zenica city is necessary since heavy metals like $\mathrm{Pb}$ and $\mathrm{Cd}$ are present preferably in respirable part of suspended particles.

\section{Literature:-}

1. Duran, F., Arnautović, Z., Galijašević, D. (1989): Situation with air quality in Zenica, Proceedings I Yugoslav congress on air pollution preservation, 2: 962-991,

2. Querol, X., Alastuey, A., Moreno, T. et al., 2008. „Spatial and temporal variations in airborne particulate matter (PM10 and PM2.5) across Spain 1999-2005“. Atmospheric Environment 42, pp 3964-79.

3. Lertxundi, A., Martinez, M. D., Ayerdi, M., Álvarez, J., Ibarluzea, J. M., 2010. „Air quality assessment in urban areas of Gipuzkoa (Spain)“ Gac Sanit. 24(3), pp 2333-2333.

4. Dockery, D.W. and Pope, C.A. (1994). Acute respiratory effects of particulate air pollution. Annu. Rev. Publ. Health. 15: 107-132.

5. World Health Organization, Regional office for Europe (2013), Health effects of particulate matter.

6. L.A.Jimoda (2012), Effects of particulate matter on human health, the ecosystem, climate and materials: a review, Working and Living environmental protection Vol 9, №1, 2013, pp 27-44. 
7. Luis Camilo Blanco-Becerra, Aurora Inés Gáfaro-Rojas, Néstor Yezid Rojas-Roa (2015), Influence of precipitation scavenging on the PM2,5/PM10 ratio at the Kennedy locality of Bogota, Kolumbia, Revista Facultad de Ingeniería, Universidad de Antioquia, No. 76, pp. 58-65, 2015.

8. EC, European Commission, DG Environment, Working Group on Arsenic, Cadmium and Nickel Compounds, 2001. Ambient Air Pollution by As, Cd and Ni compounds-Position Paper. Office for Official Publications of the European Communities, Luxembourg.

9. Goletic, S. Prcanovic, H. Beganovic, S, Durakovic, M, Karic, A, Smaijc, S. Halilovic, C. (2017), Istraživanje veze između sadržaja teških metala u taložnom prahu i zemljištu u okolini Željezare u Zenici, Project founded by the Federal ministry of education and science, Federation of Bosnia and Hercegovina.

10. Reports of Air Pollution in Zenica for considered periods, Metallurgical institute "Kemal Kapetanović" Zenica.

11. Prcanovic, H. Durakovic, M. and Beganovic, S. (2012), Concentration of Lead, Cadmium and Iron in Sediment Dust and Total Suspended Particles before and after Initialization of Integral Production in Iron and Steel Work Plant Zenica, Arh Hig Rada Toksikol 2012;63:181-188.

12. Mugica V, Marisela Mauberta, Miguel Torresa, Jose Munoza, Enrique Ricob (2001),Temporal and spatial variations of metal content in TSP and PM10 in Mexico City during 1996-1998, Aerosol Science 33 (2002) 91102.

13. Jasminka, Alijagić (2007), Distribution of chemical elements in an old Metallurgic area, Zenica (Central Bosnia), Master dissertation, Faculty of Science, University of Brno. 